\title{
Electroencephalographic Study of Gamma Rhythm in the Autobiographical Memory Evocation Mediated by Musical Stimuli
}

\author{
Maria Clara Motta Barbosa Valente', Matheus Simões Oliveira ${ }^{2}$, Karlos Eduardo Alves Silva ${ }^{1}$, \\ Berkmis Viana Santos', Janise Dal Pai ${ }^{3}$, Reginaldo Melo Filho1, Fany Pereira de Araújo Soares, \\ Júlia Maria Pacheco Lins' ${ }^{2}$, Kristiana Cerqueira Mousinho², Milton Vieira Costa ${ }^{1}$, \\ Euclides Maurício Trindade-Filho ${ }^{1,2}$

\footnotetext{
${ }^{1}$ Neurosciences and Cognition Laboratory, Universidade Estadual de Ciências da Saúde de Alagoas (UNCISAL), Maceió, AL, Brazil ${ }^{2}$ Centro Universitário CESMAC, Maceió, AL, Brazil

${ }^{3}$ Neurology and Neurosurgery Department, Universidade Federal de São Paulo (UNIFESP), São Paulo, SP, Brazil

Email: mariaclarambvalente@gmail.com
}

How to cite this paper: Valente, M.C.M.B., Oliveira, M.S., Silva, K.E.A., Santos, B.V., Pai, J.D., Filho, R.M.F., de Araújo Soares, F.P., Lins, J.M.P., Mousinho, K.C., Costa, M.V. and Trindade-Filho, E.M. (2019) Electroencephalographic Study of Gamma Rhythm in the Autobiographical Memory Evocation Mediated by Musical Stimuli. World Journal of Neuroscience, 9, 199-207. https://doi.org/10.4236/wjns.2019.93013

Received: June 4, 2019

Accepted: August 19, 2019

Published: August 22, 2019

Copyright $\odot 2019$ by author(s) and Scientific Research Publishing Inc. This work is licensed under the Creative Commons Attribution International License (CC BY 4.0).

http://creativecommons.org/licenses/by/4.0/

\begin{abstract}
Listening to music, or part of it, may stir the memory of a past moment, along with its associated emotions, such occurrences are known as autobiographical memories. Electroencephalographic (EEG) studies have shown alterations in memory recall and musical processing. However, no research was found showing a relation among music, autobiographical memories and associated emotions. The purpose of this study was to identify cortical areas involved in the evocation of autobiographical memory (associated with positive and negative events) mediated by musical stimuli. For that, gamma rhythm was analyzed through EEG recordings performed by 45 male volunteers while they were submitted to two stimuli: 1) the music capable of recalling memories associated to a positive event; 2) the music capable of evoking memories associated to a negative event. Gamma band analysis was used in search of greater brain electrical activity. As results, researchers observed increased activity in right brain hemisphere during the musical processing, besides its hypoactivation when volunteers were submitted to musical stimuli related to memories of negative events.
\end{abstract}

\section{Keywords}

Electroencephalogram, Music, Emotions, Gamma Rhythm

\section{Introduction}

Memory is classified according to two criteria: time and content. In general, 
temporal dimension is understood as ultrafast or immediate, short term and long term. According to the content, it is classified as episodic (when involved dated events) or semantics (related to timeless concepts) [1].

Episodic memory goes through time, allowing the continuity of individual identity and evocation of personal history facts, which are contextually unique, with its emotional content associated to own images and symbols, as in autobiographical memory [1] [2] [3].

Considering it, some factors, such as music, are able to elicit episodic memory, along with its associated emotions. Such occurrences are known as involuntary autobiographical memories [4]-[9].

Several studies have sought to know the brain areas associated with evocation of such memories. Studies that performed electroencephalographic (EEG) analysis of autobiographical memory evocation through a verbal stimulus, verified that memory recalling was associated to increase of alpha and beta spectral power and decrease of delta. Decrease of delta oscillations was also identified in episodes related to positive emotions, while the increase of delta was observed in aversive episodes [8].

Concerning the use of a musical stimulus, Daly et al. (2015) observed that beta oscillations were related to emotional responses induced by music, in addition, authors also verified a higher involvement of the right brain hemisphere [10].

Gamma-band is identified as the rhythm of greater brain activity. To our knowledge, there are no studies in the literature evaluating the involvement of gamma band brain activation in the evocation of autobiographical memory mediated by musical stimuli, and also describing topographically the brain areas with higher activation during the process of recalling, which are the purposes of this study.

\section{Method}

This is an analytical, observational and cross-sectional study conducted at the Neuroscience and Cognition Laboratory and was approved by the Research Ethics Committee.

\subsection{Patients}

Informed Consent Form was obtained from each participant. A total of 45 male healthy subjects, aged between 18 and 40 years old, were voluntarily selected. Researchers recruited volunteers among students from bachelor's courses of Higher Education Institutions of Alagoas.

Those individuals who: 1) had some psychiatric, neurological and/or auditory disorder; 2) were taking medicine as benzodiazepines, opioids or antipsychotics, were excluded from experiment.

\subsection{Electroencephalography}

In order to carry out the experiment, volunteers were asked to choose two kinds of music of their preference: 1) one that would remember him a remarkable 
moment of his life and able to evoke positive feelings, and 2) another that would remind the subject of a remarkable moment and elicit negative feelings. After that, each subject selected an excerpt, lasting one minute, which he considered to be the most striking of the song and should also classify the associated memory according to the division proposed by Anderson and Conway (1993). Additionally, after EEG recording, each volunteer was submitted to Likert Scale, with the purpose of evaluating the liveliness of their autobiographical memories. In this scale, volunteers should assign a value from 1 to 5 to the following question: "When I listen to the music I remember completely from the event".

EEG recordings were performed in the afternoon (2 - $6 \mathrm{pm})$, using an EMSA brand device (320 serial model). Twenty-one electrodes were placed on volunteer's scalp using as reference the international system 10 - 20. A conductive bentonite paste was used to place the electrodes and music excerpts were listened by volunteers using a headset.

Brain electrical activity signals were sampled at $256 \mathrm{~Hz}$ and filtered to less than $0.1 \mathrm{~Hz}$. EEG recordings obtained were amplified, digitized for brain mapping information analysis.

To this work, the EEG recording routine consisted of the following steps: step 1: Started with the volunteer at resting state for 5 minutes, with eyes closed, and in the absence of an external auditory and luminous stimuli; After that, step 2 was presented: The first song excerpt (lasting one minute), chosen by each volunteer, was played in a random way. In this step, volunteers should discreetly raise the index finger informing the researcher when the memory was evoked, so the researcher could point it in the EEG recording. After the first excerpt was performed, there was one minute resting without stimuli, followed by step 3: The second excerpt was played and the memory recall was recorded in the EEG. Such sequence, used in the experiment protocol, is described in Figure 1.

\subsection{Statistical Analysis}

Sample size was based on the study conducted by Knyazev and collaborators (2015) and defined as 45 individuals. Quantitative data are presented as average and standard deviation, tables and graphs are included. Analysis of variance was performed for comparing the relative power of gamma rhythm in the three conditions (resting state, first music excerpt and second music excerpt). $\mathrm{P} \leq 0.05$ was considered as value of significance for all analyzes. Gamma band was the target of this work and was also considered as a predictor of increased brain activation. Statistical analysis was performed using the BioEstat 5.3 program.

\section{Results}

From the 45 exams performed, data from 41 volunteers were used. Four samples

\begin{tabular}{|c||c|c|}
\hline $\begin{array}{c}\text { Resting state } \\
-5 \mathrm{~min}\end{array}$ & $\begin{array}{c}\text { First music } \\
\text { excerpt } 60 \mathrm{~s}\end{array}$ & $\begin{array}{c}\text { Resting state } \\
\text { (silence) } 60 \mathrm{~s}\end{array}$ \\
\hline
\end{tabular}

Figure 1. Experiment protocol sequence. 
were discarded due to the excess of artifacts, which compromised EEG analysis.

Selected data for analysis and discussion in this work were: 1) frequency of brain electrical activity in resting state and musical stimulus condition, with focus on gamma rhythm; 2) relative amplitude analysis and percentage of brain electrical frequencies; 3 ) liveliness sense gradation of autobiographical memories through the Likert scale, and; 4) Conway scale results for autobiographical memories.

Dominant frequency values were obtained from the four brain quadrants (left anterior, right anterior, left posterior and right posterior) in resting state and during music excerpt execution, pre-selected by volunteers, according to Table 1.

Data obtained showed a decrease in the delta rhythm frequency $(0-4 \mathrm{~Hz})$ of left anterior and right posterior brain quadrants. Delta band increase was evidenced in the right anterior quadrant, however, no statistical significance was found for such findings.

An overall decrease of theta rhythm $(5-8 \mathrm{~Hz})$ frequency was observed in all brain quadrants. Statistical significance was evidenced between the left anterior quadrant ( $\mathrm{p}<0.052$ ) — under positive event associated music (PEAM) stimulus and left posterior quadrant $(\mathrm{p}<0.02)$ - under negative event associated music (NEAM) stimulus.

For alpha rhythm $(9-13 \mathrm{~Hz})$ variations, a significant decrease $(\mathrm{p}<0.041)$ of spectral values under PEAM stimulus in left anterior quadrant was observed.

Concerning beta rhythm $(>14 \mathrm{~Hz})$, there was an increase in right brain quadrant under NEAM stimulus $(\mathrm{p}<0.03)$. Values of gamma rhythm $(>30 \mathrm{~Hz})$ are shown in Table 2 and Table 3.

Relative amplitude is referred to this work as the percentage of each rhythm observed in different stimuli situations (Figure 2). In this context, researchers verified a diffuse activation of both hemispheres concerning gamma band analysis

Table 1. Delta, theta, alpha, beta and gamma rhythm percentages in brain quadrants under autobiographical memory evocation mediated by musical stimuli $(\mathrm{n}=41)$.

\begin{tabular}{|c|c|c|c|c|c|c|c|c|c|c|c|c|}
\hline & \multicolumn{4}{|c|}{ Resting State } & \multicolumn{4}{|c|}{ Positive event associated music (PEAM) } & \multicolumn{4}{|c|}{ Negative event associated music (NEAM) } \\
\hline & LA & RA & LP & $\mathbf{R P}$ & LA & RA & LP & $\mathbf{R P}$ & LA & RA & LP & $\mathbf{R P}$ \\
\hline $\begin{array}{c}\text { Theta } \\
(\mathrm{X} \pm \mathrm{SD})\end{array}$ & $\begin{array}{c}5.57 \pm \\
1.75\end{array}$ & $\begin{array}{c}5.60 \pm \\
1.69\end{array}$ & $\begin{array}{c}6.37 \pm \\
1.75\end{array}$ & $\begin{array}{c}6.26 \pm \\
1.75\end{array}$ & $\begin{array}{c}4.89 \pm \\
1.52\end{array}$ & $\begin{array}{c}5.21 \pm \\
1.70\end{array}$ & $\begin{array}{c}6.43 \pm \\
1.61\end{array}$ & $\begin{array}{c}6.14 \pm \\
1.79\end{array}$ & $\begin{array}{c}5.20 \pm \\
1.67\end{array}$ & $\begin{array}{c}5.29 \pm \\
1.83\end{array}$ & $\begin{array}{c}6.05 \pm \\
1.82\end{array}$ & $\begin{array}{c}5.77 \pm \\
1.83\end{array}$ \\
\hline $\begin{array}{c}\text { Alpha } \\
(\mathrm{X} \pm \mathrm{SD})\end{array}$ & $\begin{array}{c}9.32 \pm \\
1.21\end{array}$ & $\begin{array}{c}9.13 \pm \\
1.26\end{array}$ & $\begin{array}{c}9.41 \pm \\
1.04\end{array}$ & $\begin{array}{c}9.44 \pm \\
1.18\end{array}$ & $\begin{array}{c}8.91 \pm \\
0.85\end{array}$ & $\begin{array}{c}9.41 \pm \\
1.24\end{array}$ & $\begin{array}{c}9.35 \pm \\
1.16\end{array}$ & $\begin{array}{c}9.48 \pm \\
1.21\end{array}$ & $\begin{array}{c}9.55 \pm \\
1.22\end{array}$ & $\begin{array}{c}9.37 \pm \\
1.04\end{array}$ & $\begin{array}{c}9.60 \pm \\
1.03\end{array}$ & $\begin{array}{c}9.59 \pm \\
1.16\end{array}$ \\
\hline $\begin{array}{c}\text { Beta } \\
(\mathrm{X} \pm \mathrm{SD})\end{array}$ & $\begin{array}{c}15.76 \pm \\
2.76\end{array}$ & $\begin{array}{c}15.77 \pm \\
2.92\end{array}$ & $\begin{array}{c}15.68 \pm \\
2.76\end{array}$ & $\begin{array}{c}15.83 \pm \\
2.93\end{array}$ & $\begin{array}{c}15.64 \pm \\
2.94\end{array}$ & $\begin{array}{c}16.51 \pm \\
2.69\end{array}$ & $\begin{array}{c}15.28 \pm \\
2.80\end{array}$ & $\begin{array}{c}16.12 \pm \\
2.75\end{array}$ & $\begin{array}{c}15.51 \pm \\
2.77\end{array}$ & $\begin{array}{c}16.06 \pm \\
2.89\end{array}$ & $\begin{array}{c}15.21 \pm \\
2.98\end{array}$ & $\begin{array}{c}15.87 \pm \\
2.94\end{array}$ \\
\hline $\begin{array}{c}\text { Gamma } \\
(X \pm S D)\end{array}$ & $\begin{array}{c}27.60 \pm \\
1.91\end{array}$ & $\begin{array}{c}27.40 \pm \\
1.37\end{array}$ & $\begin{array}{c}27.67 \pm \\
2.05\end{array}$ & $\begin{array}{c}27.39 \pm \\
1.44\end{array}$ & $\begin{array}{c}27.74 \pm \\
1.85\end{array}$ & $\begin{array}{c}27.76 \pm \\
2.10\end{array}$ & $\begin{array}{c}27.29 \pm \\
1.70\end{array}$ & $\begin{array}{c}27.77 \pm \\
1.85\end{array}$ & $\begin{array}{c}27.17 \pm \\
1.20\end{array}$ & $\begin{array}{c}27.40 \pm \\
1.37\end{array}$ & $\begin{array}{c}27.28 \pm \\
1.28\end{array}$ & $\begin{array}{c}27.39 \pm \\
1.44\end{array}$ \\
\hline
\end{tabular}

SD: Standard Deviation; LA: Left Anterior; RA: Right Anterior; LP: Left Posterior; RP: Right Posterior. 
Table 2. Gamma rhythm percentages in brain quadrants under autobiographical memory evocation mediated by positive event associated music stimulus $(n=41)$.

\begin{tabular}{cccc}
\hline Quadrants & Control & Positive event associated music (PEAM) & P $^{*}$ \\
\hline LA (X \pm SD) & $27.60 \pm 1.91$ & $27.74 \pm 1.85$ & 0.36 \\
RA (X \pm SD) & $27.40 \pm 1.37$ & $27.76 \pm 2.10$ & 0.09 \\
LP $(\mathrm{X} \pm \mathrm{SD})$ & $27.67 \pm 2.05$ & $27.29 \pm 1.70$ & 0.18 \\
RP $(\mathrm{X} \pm \mathrm{SD})$ & $27.39 \pm 1.44$ & $27.77 \pm 1.85$ & 0.48 \\
\hline
\end{tabular}

SD: Standard Deviation; LA: Left Anterior; RA: Right Anterior; LP: Left Posterior; RP: Right Posterior. ${ }^{\star} \mathrm{p}<$ 0.05 indicate statistically significant difference among groups.

Table 3. Gamma rhythm percentages in brain quadrants under autobiographical memory evocation mediated by negative events associated music stimulus $(n=41)$.

\begin{tabular}{cccc}
\hline Quadrants & Control stimuli & Negative event associated music (NEAM) & $\mathrm{P}^{*}$ \\
\hline LA (X \pm SD) & $27.60 \pm 1.91$ & $27.17 \pm 1.20$ & 0.20 \\
RA (X \pm SD) & $27.40 \pm 1.37$ & $27.40 \pm 1.37$ & 0.13 \\
LP (X \pm SD) & $27.67 \pm 2.05$ & $27.28 \pm 1.28$ & 0.04 \\
RP $(\mathrm{X} \pm$ SD) & $27.39 \pm 1.44$ & $27.39 \pm 1.44$ & 0.38 \\
\hline
\end{tabular}

SD: Standard Deviation; LA: Left Anterior; RA: Right Anterior; LP: Left Posterior; RP: Right Posterior. ${ }^{\star} \mathrm{p}<$ 0.05 indicate statistically significant difference among groups.

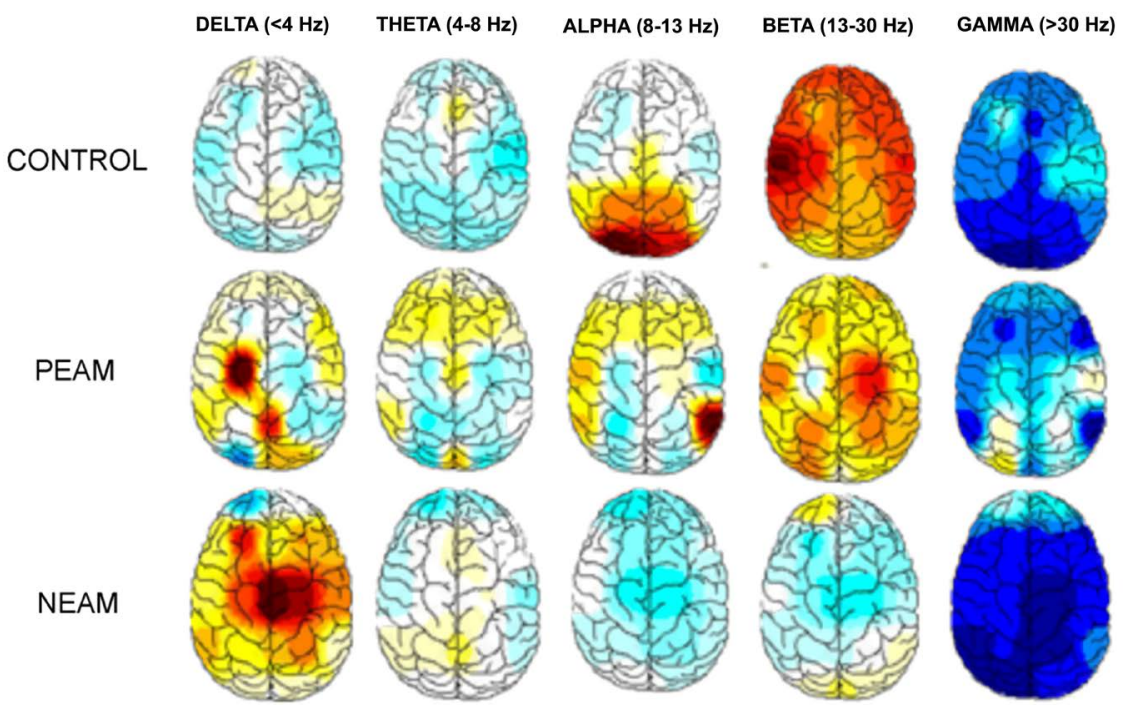

Figure 2. Relative amplitude percentage of each rhythm observed in different stimuli situations. Autobiographical memory for events was classified according to Conway's Scale, while liveliness was graded using the Likert Scale. Most events were classified as "intermediate" (NEAM: 15 and PEAM: 11) according to Conway and score 5 for liveliness on Likert scale (NEAM: 17 and PEAM: 21).

under PEAM stimulus. However, under NEAM stimulus a complete decrease activity was shown in both hemispheres, while a greater electrical activation was detected in brain frontal area. Concerning analysis of other rhythms, a beta predominance was observed during PEAM stimulus and delta prevalence was de- 
tected under NEAM stimulus.

\section{Discussion}

Several studies have shown that listening to music leads to variation of several frequency bands, since it is a complex phenomenon and requires extensive functional coordination and communication among different brain areas [11].

In this study, we attempted to verify changes observed in different brain frequencies in evoking autobiographical memory mediated by musical stimuli, as well as the electrical activity of the four brain quadrants. For that, frequencies changes activities in the different quadrants and also its percentage were evaluated. Focus was given to higher gamma band activity in cortical areas, gammaband frequency was determined as above $30 \mathrm{~Hz}$.

Concerning delta band analysis, results showed frequency decrease in left anterior and right posterior brain quadrants, F3-F7-T3-C3 and T6-P4-O2, respectively, while higher band frequency was verified in left posterior quadrant (T5-P3-O1). The right anterior quadrant (F4-F8-T4-C4) presented decrease in delta activity during PEAM and increase activity under NEAM stimulus. This finding may corroborate with Knyazev and collaborators (2015) who verified a decrease in delta band usually followed by recalling processes. Authors also observed decrease of delta oscillations in episodes of positive emotions and increase of delta band activity in aversive episodes [12]. This was also verified in this work by increasing the percentage of delta waves during NEAM stimulus.

Regarding theta rhythm analysis, an overall decrease in frequency was observed in all brain quadrants. This may suggest a lower liveliness sense in autobiographical memories, since theta oscillations are positively correlated to this finding [12] [13].

For alpha, asymmetry of brain electrical activity was identified, especially considering left anterior quadrant reactivity, which showed decrease of alpha frequency compared to resting state. This was already demonstrated by Morais (2016), who also observed that music with higher excitation levels translates into increased global frontal activity, while music with lower excitation induces to less activity [14]. Researchers of this work observed the same response since there was a decrease of alpha and increase of gamma rhythm percentage in left anterior brain quadrant.

This work showed that increase of beta-band activity positively correlates with NEAM stimulus in the right anterior brain quadrant $(\mathrm{p}<0.03)$, which is similar to findings of Shahabi and collaborators (2016) [15]. However, beta activity seems to be the main frequency throughout the brain under PEAM stimulation, which demonstrates its participation in this process.

Verifying the brain involvement, that is, augmentation of electrical activity under NEAM and PEAM stimuli, was one of the main purposes of this work. For that, analysis of gamma values obtained from EEG recording was performed, since it reflects the neuronal activity of a given brain area. 
In this sense, results showed increase in gamma values under PEAM stimulation in left anterior, right anterior and right posterior brain quadrants, which may guide the role of such areas in musical processing, however, statistical significance was not found. Regarding NEAM stimulus, a decrease in gamma band values was observed throughout left brain hemisphere, demonstrating a less activation of this area. Wu et al. (2012) and Daly et al. (2015) showed increased electrical activation in right brain hemisphere during musical processing [11] [16]. Such authors observed cortical lateralization pattern in musical perception. In this work, researchers found that such activation may be influenced by emotional aspects related to memories.

Another factor to consider is the model of Valencia and Alert or Excitement. According to it, the right brain hemisphere is related to feelings of happiness and calm, while the left hemisphere is related to fear, sadness and anger. Such correlation was not reproduced in this study, despite a positive association between the right hemisphere activation and PEAM stimulation, which was not observed for left hemisphere and NEAM stimulus. Methodology of this work did not specify positive or negative valences (eg: anger, fear, nervousness, joy), which have probably unable researchers in establishing a relationship with greater precision [17].

Another point of discussion is the relation between autobiographical memories evocation and EEG activity. Memory recovery is influenced by the degree in which it is organized, stored and its evocation frequency [18]. In this aspect, $41.46 \%$ of the individuals scored a high degree of liveliness in memory recall under PEAM stimulus and 51.21\% under NEAM stimulus. This may be explained by the fact that each individual selected a musical excerpt of their preference, which was able to stimulate memories more efficiently than when submitted to an unknown excerpt. Although musical stimulation did not follow a particular pattern, because each volunteer selected music of own preference, a high degree of liveliness in recalling their memories was achieved, showing that this is an effective way of extracting such episodic memories.

In this work, authors were able to evidence a greater asymmetric activation between brain hemispheres in musical processing when associated with emotional aspects. However, limitations included the precision in identifying brain areas being activated, which would be possible using isolated electrode analysis. Another point is, the feeling bound to different memories was not specified in this work. In addition, during EEG recording and exposure of volunteers to musical excerpt, authors observed greater brain activity in the first twenty seconds of each excerpt, which may limit the time of EEG analysis. Authors believe that these findings may lead to significant EEG changes.

\section{Conclusion}

In this sense, emotions related to music and memory showed to be associated to different brain areas. In this study, the right brain hemisphere showed to be more activated than the left one during music stimuli. Besides this, in the ab- 
sence of stimuli, the left brain hemisphere showed decreased activity than the right one. Thus, further researches are necessary for understanding the role that such structures may have in this process.

\section{Conflicts of Interest}

The authors declare no conflicts of interest regarding the publication of this paper.

\section{References}

[1] Izquierdo, I. (2011) Memória. 2nd Edition, Artmed, Porto Alegre.

[2] Frank, J. and Landeira-Fernandez, J. (2006) Rememoração, subjetividade e as bases neurais da memória autobiográfica. Psicologia Clínica, 18, 35-47. https://doi.org/10.1590/S0103-56652006000100004

[3] Gauer, G. and Gomes, W.B. (2008) Recordação autobiográfica: Reconsiderando dados fenomenais e correlatos neurais. Aletheia, 27, 36-50.

[4] Fernandes-Filho, E.S., de Oliveira Lima, T., Silva, D., Costa, M. and Filho, E. (2016) Study of Brain Activation Using Electroencephalographic Technique for Performing Short-Term Memory Tests. World Journal of Neuroscience, 6, 37-42. https://doi.org/10.4236/wjns.2016.61005

[5] Janata, P., Tomic, S.T. and Rakowski, S.K. (2007) Characterisation of Music-Evoked Autobiographical Memories. Memory, 15, 845-860. https://doi.org/10.1080/09658210701734593

[6] Koelsch, S. (2010) Towards a Neural Basis of Music-Evoked Emotions. Trends in Cognitive Sciences, 14, 131-137. https://doi.org/10.1016/j.tics.2010.01.002

[7] El-Haj, M., Fasotti, L. and Allain, P. (2012) The Involuntary Nature of Music-Evoked Autobiographical Memories in Alzheimer's Disease. Consciousness and Cognition, 21, 238-246.

[8] Berntsen, D., Rubin, D.C. and Salgado, S. (2015) The Frequency of Involuntary Autobiographical Memories and Future Thoughts in Relation to Daydreaming, Emotional Distress, and Age. Consciousness and Cognition, 36, 352-372.

[9] Berntsen, D. and Rasmussen, A. (2009) The Possible Functions of Involuntary Autobiographical Memories. Applied Cognitive Psychology, 23, 1137-1152. https://doi.org/10.1002/acp.1615

[10] Daly, I., et al. (2015) Music-Induced Emotions Can Be Predicted from a Combination of Brain Activity and Acoustic Features. Brain and Cognition, 101, 1-11. https://doi.org/10.1016/j.bandc.2015.08.003

[11] Anderson, A.J. and Conway, M.A. (1993) Investigating the Structure of Autobiographical Memories. Journal of Experimental Psychology, 19, 1178-1196. https://doi.org/10.1037/0278-7393.19.5.1178

[12] Knyazev, G.G., et al. (2015) Oscillatory Correlates of Autobiographical Memory. International Journal of Psychophysiology, 95, 322-332. https://doi.org/10.1016/j.ijpsycho.2014.12.006

[13] Nemati, S., Akrami, H., Salehi, S., Esteky, H. and Moghimi, S. (2019) Lost in Music: Neural Signature of Pleasure and Its Role in Modulating Attentional Resources. Brain Research, 1711, 7-15. https://doi.org/10.1016/j.brainres.2019.01.011

[14] Morais, M.F.O. (2016) Estudo da Influência da Música na Atividade Elétrica Cerebral. Tese (Mestrado em Engenharia Biomédica)-Faculdade de Ciências e 
Tecnologia, Universidade Nova de Lisboa, Lisboa.

[15] Shahabi, H. and Moghimi, S. (2016) Toward Automatic Detection of Brain Responses to Emotional Music through Analysis of EEG Effective Connectivity. Computers in Human Behavior, 58, 231-239. https://doi.org/10.1016/j.chb.2016.01.005

[16] Wu, J., Zhang, J., Liu, C., Liu, D., Ding, X. and Zhou, C. (2012) Graph Theoretical Analysis of EEG Functional Connectivity during Music Perception. Brain Research, 1483, 71-81. https://doi.org/10.1016/j.brainres.2012.09.014

[17] Aurélio, J. and Cláudio, V. (2009) Congruência de humor em memórias autobiográficas de infância de indivíduos com depressão. Análise Psicológica, 27, 159-173.

https://doi.org/10.14417/ap.196

[18] Höller, Y., Thomschewski, A., Schmid, E.V., Höller, P., Crone, J.S. and Trinka, E. (2012) Individual Brain-Frequency Responses to Self-Selected Music. International Journal of Psychophysiology, 86, 206-213.

https://doi.org/10.1016/j.ijpsycho.2012.09.005 